\title{
Oxymatrine and its metabolite matrine contribute to the hepatotoxicity induced by radix Sophorae tonkinensis in mice
}

\author{
YINGMIN GU ${ }^{1,2^{*}}$, JINYAO LU ${ }^{1,2^{*}}$, WEI SUN ${ }^{1,2}$, RUOMIN JIN $^{1,2}$, TOKO OHIRA $^{3}$, \\ ZEAN ZHANG $^{1,2}$ and XUESONG TIAN ${ }^{1,2}$
}

\author{
${ }^{1}$ Center for Drug Safety Evaluation and Research; ${ }^{2}$ Center for Laboratory Animals, \\ Shanghai University of Traditional Chinese Medicine, Shanghai 201203; ${ }^{3}$ Shanghai Innostar Biotech Co., Ltd., \\ China National Shanghai Center for New Drug Safety Evaluation and Research, Shanghai 201203, P.R. China
}

Received June 19, 2018; Accepted December 28, 2018

DOI: $10.3892 / \mathrm{etm} .2019 .7237$

\begin{abstract}
Previous studies by our group demonstrated that radix Sophorae tonkinensis could induce hepatotoxicity. However, it remains unclear which components of this herb may be responsible for its hepatotoxicity. The present study aimed to investigate the hepatic toxicity of treatment with matrine (MT) and oxymatrine (OMT) alone or simultaneously. Furthermore, the current study aimed to identify whether the hepatotoxicity induced by OMT is actually the toxic characterization of its metabolite MT. Hepatotoxicity was evaluated by biochemical and histopathological approaches in subchronic toxicity in mice, as well as via evaluation of cytotoxicity and enzyme leakage in AML12 liver cells. The results indicated that treatment of mice with OMT and MT individually or simultaneously resulted in centrilobular hypertrophy in the liver at doses equivalent to that contained in radix $S$. tonkinensis at a hepatotoxic dose, suggesting that MT and OMT are likely hepatotoxic components of this herb. OMT-induced hepatotoxicity may be primarily exerted via its metabolite MT in mice. Furthermore, OMT combined with MT was observed to be more toxic compared with OMT or MT alone. These results extend our understanding of the hepatotoxicity of radix $S$. tonkinensis and its active ingredients.
\end{abstract}

\section{Introduction}

Radix Sophorae tonkinensis, the dried roots and rhizomes of S. tonkinensis Gapnep., is a well-known traditional Chinese

Correspondence to: Dr Zean Zhang or Dr Xuesong Tian, Center for Drug Safety Evaluation and Research, Shanghai University of Traditional Chinese Medicine, 1200 Cailun Road, Shanghai 201203, P.R. China

E-mail: zza@shutcm.edu.cn

E-mail: xuesong.tian@shutcm.edu.cn

*Contributed equally

Key words: radix Sophorae tonkinensis, oxymatrine, matrine, hepatotoxicity, mice, AML12 liver cells medicine (TCM) herb and is primarily distributed in the southwest provinces of China (1). It has been widely used in clinics to treat sore throats, viral hepatitis and jaundice $(1,2)$. Radix S.tonkinensis was first described in Kaibao Materia Medica, the earlier Pharmacopoeia of China in Northern Song (968-976 AD) (2). In addition to studies investigating the molecular mechanisms of its pharmacological activities, much attention has recently been focused on the side effects of radix $S$. tonkinensis, including neurological toxicity and liver toxicity. Liver toxicities following intoxication with radix S. tonkinensis are less well known compared with its neurological complications (3). However, it has been reported in clinical settings that liver function is abnormal, as evidenced by an increase in the levels of serum alanine aminotransferase (ALT), aspartate aminotransferase (AST) and total bilirubin (TBil), after treatment with this herb (4). A recent study by our group revealed that single and repeated oral administration with extracts of radix $S$.tonkinensis may induce hepatotoxicity and even mortality in mice in a dose-dependent manner (5).

The known major chemical components of radix S. tonkinensis include quinolizidine alkaloids, flavonoids and triterpenoids (6). However, it remains poorly understood which component(s) of this herb is responsible for its hepatotoxic effects. Oxymatrine (OMT; Fig. 1A) and matrine (MT; Fig. 1B) are the two major quinolizidine alkaloids found in the herb, and have long been regarded as the main active components contributing to the pharmacological properties of radix S.tonkinensis $(7,8)$. The hepatotoxicity of OMT and MT has been gradually documented in the literature. It was reported that treatment with large doses of OMT in mice for 7 days caused abnormal liver function (9). Furthermore, OMT worsened liver damage in patients with hepatitis B (10). Our group has demonstrated that single oral administration with large doses of OMT or MT induced hepatotoxicity and even mortality in mice (11). Taken together, these results indicate that OMT and MT may be responsible for the hepatotoxicity of radix $S$. tonkinensis. In addition to the alkaloids, it has been reported that the non-alkaloid components of radix $S$. tonkinensis, including flavonoids and triterpenoids, induce marked cytotoxicity in zebrafish and HepG2 cells, with lethal concentration 50 and half maximal inhibitory concentration $\left(\mathrm{IC}_{50}\right)$ values of 0.43 and $0.98 \mathrm{mg} / \mathrm{ml}$, respectively (12). In 
that study, the non-alkaloid part of the herb was identified to be the hepatotoxic constituent, while the alkaloid part did not exhibit hepatotoxicity (12). To date, no adverse effects or toxicity caused by the flavonoids or triterpenoids alone in radix S. tonkinensis have been reported. Therefore, it is important to verify which components of this herb may be responsible for its hepatotoxicity.

To the best of our knowledge, previous studies have examined the effects of administration of a large dose of OMT, MT or the non-alkaloid components to investigate the cause of radix $S$. tonkinensis-induced hepatotoxicity however, no studies have reported the toxic effects of the components at the equivalent amounts contained in radix $S$. tonkinensis that can induce hepatotoxicity. Since MT and OMT are regarded as the 'marker compounds' of this herb, and the main clinical applications of MT and OMT are treatment of patients with cancer, viral hepatitis, cardiac diseases and skin diseases $(7,8)$, the current study investigated the hepatotoxicity of MT and OMT.

Metabolism is an important pharmacokinetic process that influences the biological activity and toxicity of drugs in vivo (13). Certain components of a drug can be converted to toxic metabolites, while other components are transformed to non-toxic metabolites (14). It has been reported that when taken orally, the majority of OMT is transformed into the more absorbable metabolite MT by intestinal bacteria in the gastrointestinal tract (15). The metabolite MT may have pharmacological and toxicological implications $(16,17)$. However, there is little information on the role of the active metabolite MT in the toxicity of OMT after oral administration. Therefore, it is necessary to compare the hepatic toxicity of OMT with its active metabolite MT.

The primary aims of this study were to investigate: i) Whether or not MT and OMT are responsible for the hepatotoxicity of radix $S$. tonkinensis; and ii) whether the hepatotoxicity induced by OMT in mice is primarily caused by OMT itself or by the subsequent transformation to its active metabolite MT.

\section{Materials and methods}

Materials. OMT (cat. no. 150629) and MT (cat. no. 160930) were purchased from Shanghai Winherb Medical Technology Co., Ltd. (Shanghai, China) with a purity of $\geq 99 \%$. Stock solutions of OMT $(10 \mathrm{mg} / \mathrm{ml})$, MT $(10 \mathrm{mg} / \mathrm{ml})$ and OMT + MT $(10+10 \mathrm{mg} / \mathrm{ml})$ were prepared with distilled water and stored at $-20^{\circ} \mathrm{C}$ for the subchronic toxicity study. For cell cytotoxicity studies, OMT, MT and OMT + MT were separately dissolved with phosphate-buffered saline ( $\mathrm{pH} 7.2)$, and then filtered $(0.22 \mu \mathrm{m})$ to obtain stock solutions ( $\leq 400 \mathrm{mM})$. Immediately before use, the stock solution was diluted in cell culture medium (DMEM/F-12 supplemented with heat-inactivated $10 \%$ fetal bovine serum; each, Gibco; Thermo Fisher Scientific, Inc., Waltham, MA, USA) to the expected concentrations. Commercially biochemical identification kits for determining ALT [Reagent (R)-I: cat. no. F661, R-II: cat. no. H657], AST (R-I: cat. no. I663, R-II: cat. no. G656), TBil (R-I: cat. no. DR066, R-II: cat. no. DR067) and lactic dehydrogenase (LDH; R-I: cat. no. K553, R-II: cat. no. K554) were provided by Shino-Test Corporation (Tokyo, Japan).
Isoflurane (cat. no. 130302) was obtained from Hebei Yipin Pharmaceutical Co., Ltd. (Shijiazhuang, China). Dulbecco's modified Eagle's medium/nutrient mixture F-12 (DMEM/F-12; cat. no. 11330-032), penicillin-streptomycin (cat. no. 15140-122) and fetal bovine serum (FBS; cat. no. 10099-141) were purchased from Gibco (Thermo Fisher Scientific, Inc.). Insulin, transferrin and sodium selenite (ITS) liquid media supplement (cat. no. I3146) and dexamethasone (cat. no. D4902) were from Sigma-Aldrich (Merck KGaA, Darmstadt, Germany). The Cell Counting Kit-8 (CCK-8; cat. no. C0037) assay was purchased from Beyotime Institute of Biotechnology (Shanghai, China).

Animals. A total of 44 male specific-pathogen-free C57BL/6 mice (certificate no. 2008001653092; age, 35 days; weight, 18-20 g), were obtained from Shanghai SIPPR-BK Laboratory Animal Co., Ltd. (Shanghai, China). Mice were housed in cages (5 or 6 animals/cage) with ad libitum access to standard diet and drinking water under controlled conditions (temperature, $23 \pm 1^{\circ} \mathrm{C}$; relative humidity, $53-65 \%$; 12-h light-dark cycle) for at least 2 days prior to the experiments at the Center for Laboratory Animals of the Center for Drug Safety Evaluation and Research, Shanghai University of Traditional Chinese Medicine (Shanghai, China). The experimental procedures were approved by the Animal Ethics Committee of Shanghai University of Traditional Chinese Medicine (certificate no. SZY201504021) and performed in accordance with the Guidelines for the Care and Use of Laboratory Animals (National Institutes of Health, Bethesda, MD, USA) (18). The experiments were also conducted according to the standards of The Guidelines of Test Technology for Long-Term Toxicity of Chemical Drugs (19).

Subchronic toxicity study. A total of 44 male C57BL/6 mice used in this study were randomly divided into four experimental groups, with 11 mice/group. In a previous study by our group, moderate centrilobular hypertrophy was observed in the mice treated with $2.5 \mathrm{~g} / \mathrm{kg}$ radix $S$. tonkinensis extracts, in which the calculated contents of OMT and MT were 40.5 and $69.1 \mathrm{mg} / \mathrm{kg}$, respectively (5). Therefore, these were used as the working dosages in the current study. The stock solution was diluted immediately prior to the experiment in distilled water to the expected concentrations: OMT $(2.025 \mathrm{mg} / \mathrm{ml}), \mathrm{MT}$ $(3.455 \mathrm{mg} / \mathrm{ml})$ and OMT + MT $(2.025+3.455 \mathrm{mg} / \mathrm{ml})$. Each group was scheduled for 90 -day oral gavage ( $20 \mathrm{ml} / \mathrm{kg}$ body weight). Finally, groups were orally treated with OMT $(40.5 \mathrm{mg} / \mathrm{kg}), \mathrm{MT}$ $(69.1 \mathrm{mg} / \mathrm{kg})$ and OMT + MT $(40.5+69.1 \mathrm{mg} / \mathrm{kg})$ for 90 days, while the control group was treated with distilled water. During the treatment period, mice were weighed each week. At the end of the administration period, animals were fasted for $4 \mathrm{~h}$, with water ad libitum. They were subsequently anesthetized with isoflurane, and blood samples were collected from the abdominal vein of all mice for analysis of serum biochemistry. After blood collection, the animals were sacrificed and their livers were collected for histopathological examination.

Analysis of serum biochemistry. The serum was obtained from whole blood centrifuged at 2,010 x $\mathrm{g}$ for $15 \mathrm{~min}$ at room temperature. For the assessment of liver function, ALT, AST and TBil levels were determined using a Hitachi 7080 

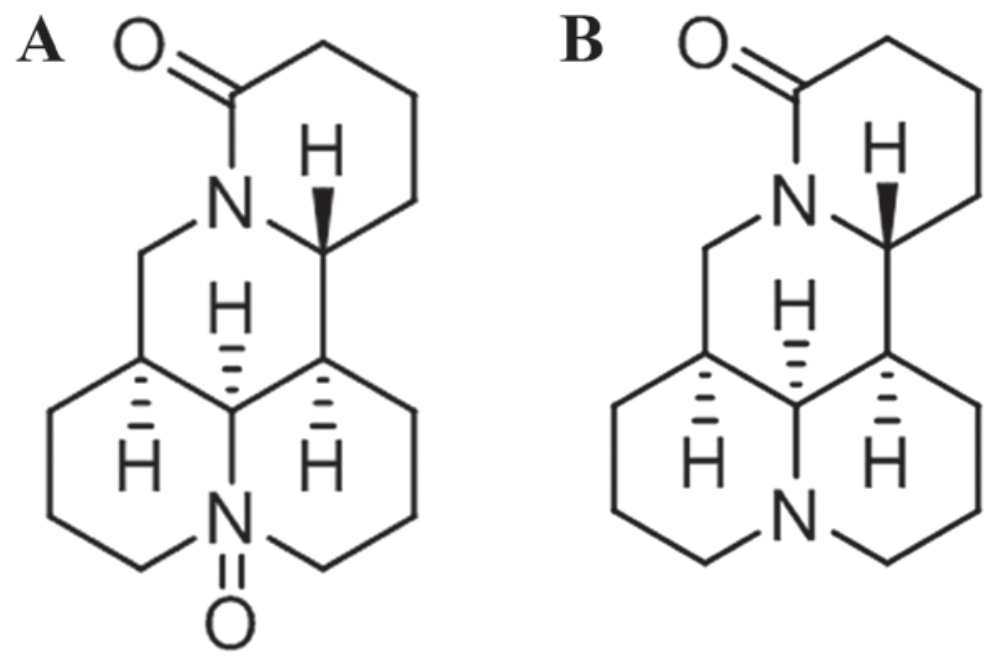

Figure 1. Chemical structures of (A) oxymatrine and (B) matrine.

automatic biochemistry analyzer (Hitachi, Ltd., Tokyo, Japan) following use of the aforementioned kits.

Histopathological examination. Livers were fixed in $10 \%$ neutral buffered formalin for 3 days at room temperature, embedded in paraffin, cut into $4-\mu$ m-thick sections, deparaffinized in xylene at room temperature and serially rehydrated in decreasing concentrations of ethanol at room temperature. Sections were stained with hematoxylin $(10 \mathrm{~min})$ and eosin (3 min) at room temperature and examined under a light microscope to evaluate tissue structure.

Cell culture. The mouse hepatocyte cell line AML12 was generously provided by Dr Qin Feng from Shuguang Hospital, Shanghai University of Traditional Chinese Medicine. AML12 liver cells were cultured in DMEM/F12 medium supplemented with $10 \% \mathrm{FBS}, 100 \mathrm{IU} / \mathrm{ml}$ of penicillin, $100 \mu \mathrm{g} / \mathrm{ml}$ of streptomycin, ITS liquid media supplement and $40 \mathrm{ng} / \mathrm{ml}$ dexamethasone. All cells were incubated at $37^{\circ} \mathrm{C}$ under a humidified atmosphere of $5 \% \mathrm{CO}_{2}$.

Cell viability and cytotoxicity. The inhibitory effects of OMT, MT and OMT + MT on the growth of AML12 cells were tested using the CCK- 8 assay, may be more suitable compared with MTT for analyzing cell proliferation, as it can be reduced to soluble formazan by dehydrogenase in mitochondria and induces little toxicity to cells (20). Briefly, cells were seeded at a density of $5 \times 10^{3}$ cells/well in a 96-well flat-bottomed plate and incubated for $24 \mathrm{~h}$ at $37^{\circ} \mathrm{C}$ with $5 \% \mathrm{CO}_{2}$. Cells were then incubated with culture medium containing various concentrations of OMT $(10,20,30$ and $40 \mathrm{mM}), \mathrm{MT}(10,14,18,22,26$ and $30 \mathrm{mM})$ or OMT + MT (10, 14, 18, 22, 26 and $30 \mathrm{mM}$ each) for further $24 \mathrm{~h}$. After $10 \mu \mathrm{l} \mathrm{CCK-8} \mathrm{dye} \mathrm{was} \mathrm{added} \mathrm{to} \mathrm{each} \mathrm{well,} \mathrm{cells} \mathrm{were}$ incubated at $37^{\circ} \mathrm{C}$ for $2 \mathrm{~h}$ and the absorbance was finally determined at $450 \mathrm{~nm}$ using a microplate reader (Synergy2; BioTek Instruments, Inc., Winooski, VT, USA). Results were expressed as a percentage calculated from the ratio of the absorbance of treated cells to untreated cells. The concentration that caused a $50 \%$ loss of cell growth, $\mathrm{IC}_{50}$, was used as an indication of OMT, $\mathrm{MT}$ and OMT + MT growth inhibition potency.
ALT, AST and LDH leakage. The levels of extracellular ALT, AST and LDH in the culture medium were measured using a Hitachi 7080 automatic biochemistry analyzer. Briefly, AML12 liver cells $\left(5 \times 10^{3}\right.$ cells/well) in a 96-well flat-bottomed plate were incubated for $24 \mathrm{~h}$, then the cells were incubated with culture medium containing various concentrations of OMT (18 mM), MT (6, 12 and $18 \mathrm{mM})$ or OMT + MT $(4,10$ and $16 \mathrm{mM}$ each) for 3, 6, 12 and $24 \mathrm{~h}$. Control cells received only solvent (cell culture medium) instead of OMT, MT or OMT + MT. Following 3, 6, 12 and $24 \mathrm{~h}$ of treatment, cell culture media from each of the 96 wells were collected and centrifuged at $1,000 \mathrm{x}$ g for $10 \mathrm{~min}$ at $4^{\circ} \mathrm{C}$. The supernatant was collected for further tests (ALT, AST and LDH determination as aforementioned) by a Hitachi 7080 automatic biochemistry analyzer (Hitachi, Ltd., Tokyo, Japan).

Cell morphology observation. AML12 liver cells were seeded into 6 -well plate $\left(5 \times 10^{4}\right.$ cells/well $)$ and cultured at $37^{\circ} \mathrm{C}$ for $24 \mathrm{~h}$. The culture medium was then removed and subsequently replaced with fresh culture medium containing MT (18 mM), OMT (18 mM) or MT + MT (16 mM) and incubated for a further $6 \mathrm{~h}$, while cells cultured in fresh culture medium only served as a control. At $6 \mathrm{~h}$ time points, cells were observed and photographed immediately with an Olympus X51 inverted microscope (Olympus Corporation, Tokyo, Japan).

Statistical analysis. SPSS (version 24; IBM Corp., Armonk, NY, USA) and SigmaPlot (version 11.0; Systat Software Inc., Chicago, IL, USA) software were used for statistical analysis. Data are presented as the mean \pm standard error. When equal variance was assumed, the data were analyzed using one-way analysis of variance followed by least significant difference (LST) post-hoc test for multiple comparisons. $\mathrm{P}<0.05$ was considered as statistically significant. When equal variance was not assumed, the data were compared using the non-parametric test. To avoid false positives caused by multiple comparisons, a Bonferroni's correction was performed to adjust the test level $(0.05 / \mathrm{n}) . \mathrm{P}<0.05$ was considered to indicate a statistically significant difference. 

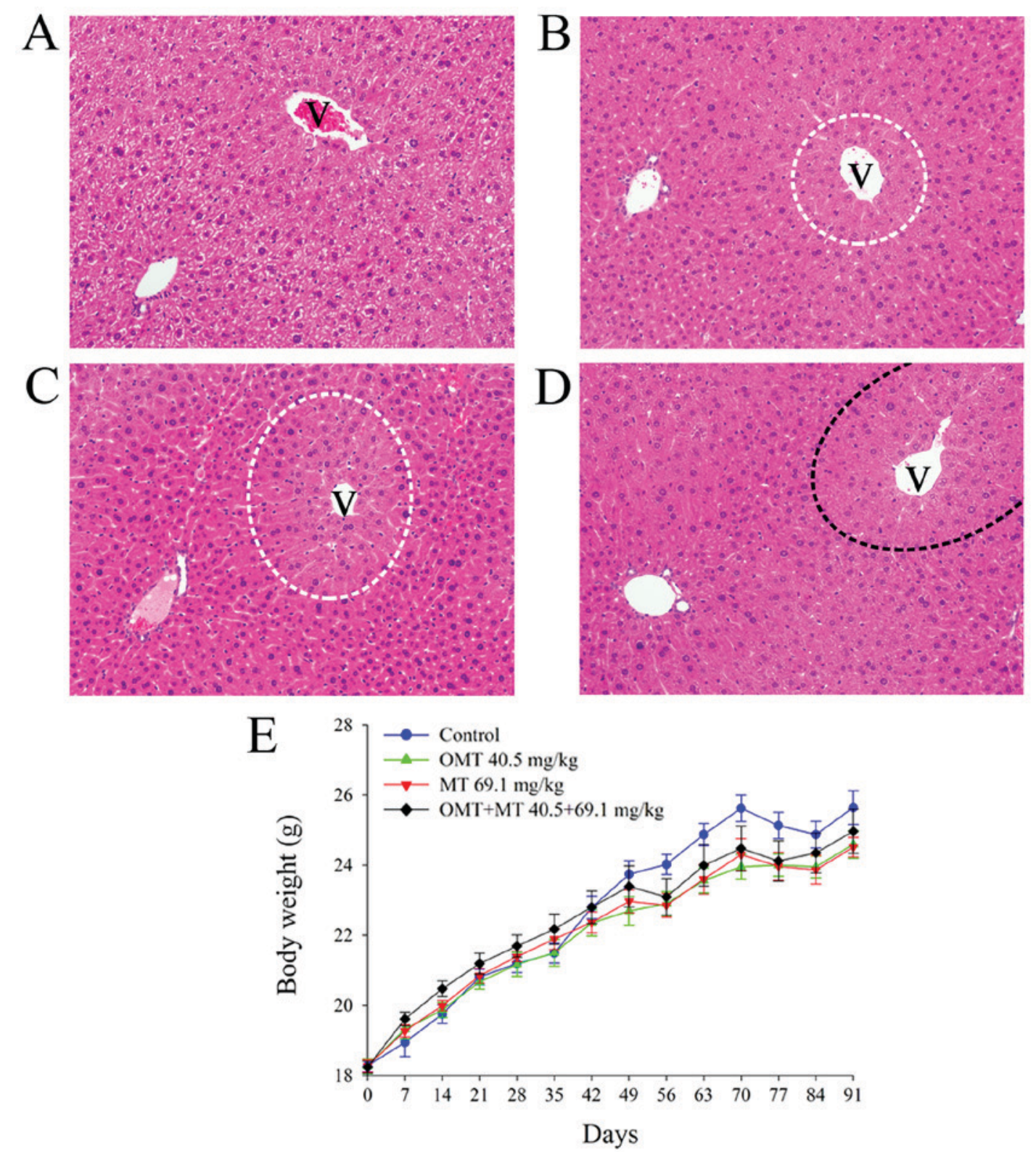

Figure 2. Comparison of histopathology and body weight after 90 days of treatment with OMT, MT or OMT + MT in mice (magnification, x200). (A) No histological changes were observed in the control mice. Mild centrilobular hypertrophy (areas circled with white dotted lines) was observed in (B) OMT and (C) MT groups. (D) Moderate centrilobular hypertrophy (area circled with a black dotted line) was observed in OMT + MT-treated mice. (E) Body weights of mice treated with OMT, MT or OMT + MT for 90 days. Data are expressed as the mean \pm standard error of the mean (n=9-11). OMT, oxymatrine; MT, matrine; $\mathrm{V}$, central vein.

\section{Results}

Effects of OMT, MT and OMT + MT on histopathology, biochemistry and body weight in mice. Toxicity induced by 90-day oral administration of OMT and/or MT in mice was studied by evaluating body weight, histopathology and biochemistry (Fig. 2). No signs of toxicity (including hypoactivity and alterations in locomotor activity) or cases of mortality were observed during the administration of OMT, MT and OMT + MT at doses of 40.5, 69.1 and 40.5+69.1 mg/kg, respectively. Since body weight changes and growth rate in prolonged toxicity studies are important indicators of adverse effects of drugs and chemicals on laboratory animals (21), body weight was monitored in the mice used in the current study. The body weight of the control group was slightly lower prior to day 35 and then exceeded the treated groups following day 49 , but the differences were not statistically significant (P>0.05; Fig. 2E), which suggested that the 90-day oral administration of OMT, MT and OMT + MT had no obvious effect on the normal growth of mice. Serum biochemistry serves as an important indicator of physiological abnormalities in liver intoxication (22). The values of biochemical indicators following 90 days of exposure to OMT, MT and OMT + MT are presented in Table I. It was observed levels of serum ALT were significantly higher in OMT-treated mice and levels of AST were significantly higher in MT-treated mice compared with control mice $(\mathrm{P}<0.05$; Table I). Although animals treated with OMT showed higher ALT and treated with MT exhibited higher AST, compared with the control group, these parameters were within normal range for the species utilized 
Table I. Comparison of serum biochemistry after 90 days of treatment with OMT, MT or OMT + MT in mice.

\begin{tabular}{lccc}
\hline Group & ALT, IU/1 & AST, IU/l & TBil, mmol/1 \\
\hline Control $(\mathrm{n}=10)$ & $21.50 \pm 0.82$ & $38.10 \pm 1.57$ & $1.57 \pm 0.09$ \\
OMT, $40.5 \mathrm{mg} / \mathrm{kg}(\mathrm{n}=9)$ & $25.11 \pm 1.23^{\mathrm{a}}$ & $43.33 \pm 2.41$ & $1.28 \pm 0.07$ \\
MT, 69.1 mg/kg $(\mathrm{n}=11)$ & $22.09 \pm 0.84$ & $44.82 \pm 2.55^{\mathrm{a}}$ & $1.56 \pm 0.22$ \\
OMT + MT, 40.5+69.1 mg/kg (n=11) & $22.27 \pm 1.20$ & $39.82 \pm 1.55$ & $1.52 \pm 0.28$ \\
\hline
\end{tabular}

${ }^{\mathrm{a}} \mathrm{P}<0.05$ vs. control group. OMT, oxymatrine; MT, matrine; ALT, alanine aminotransferase; AST, aspartate aminotransferase; TBil, total bilirubin.

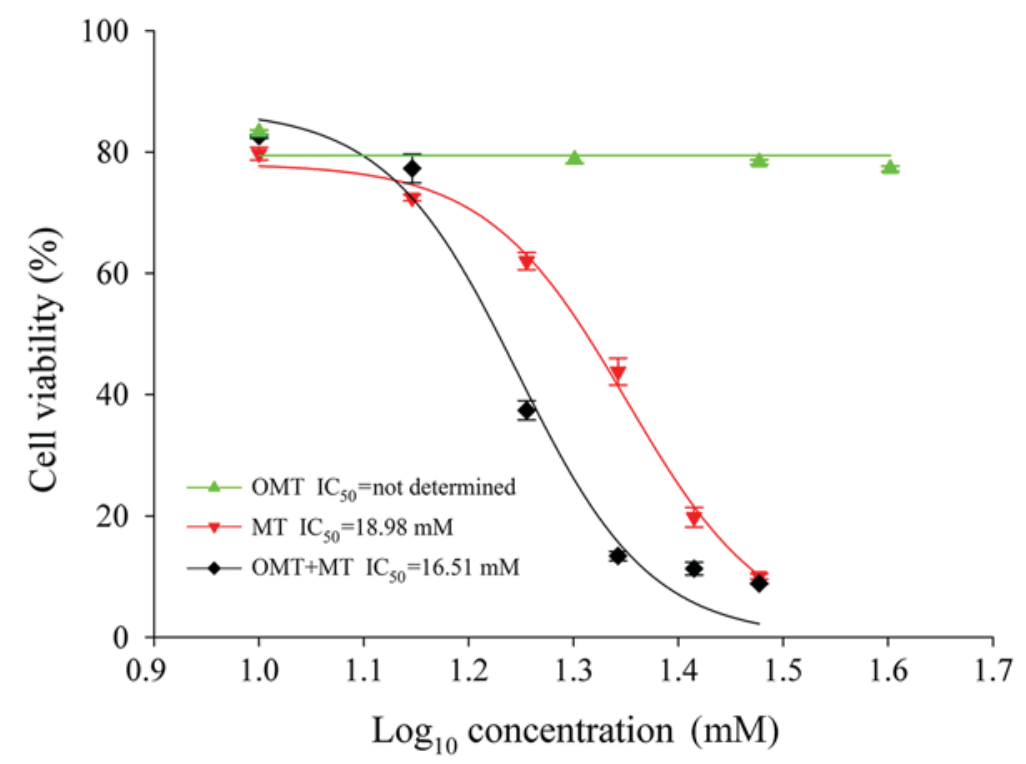

Figure 3. Comparison of $\mathrm{IC}_{50}$ of OMT, MT or OMT + MT treatment in AML12 liver cells. After 24 h of treatment, cell viability was determined using CCK-8 assays. Data were fitted using SigmaPlot 11.0 software to calculate the $\log _{10}$ of the concentration of the inhibitor vs. percentage cell viability. The $\mathrm{X}$-axis values are presented as the $\log$ of compound concentration $(0-40 \mathrm{mM})$. The $\mathrm{IC}_{50}$ values were $18.98 \mathrm{mM}$ for MT and 16.51 for OMT $+\mathrm{MT}^{\mathrm{T}} \mathrm{The} \mathrm{IC}_{50}$ of OMT could not be determined at $24 \mathrm{~h}$. Data are presented as the mean \pm standard error of the mean $(\mathrm{n}=4)$. OMT, oxymatrine; MT, matrine; IC ${ }_{50}$, half maximal inhibitory concentration.

in the current study, which was also congruent to a previous study (23). Compared with the control, no significant alterations in TBil levels were observed in OMT, MT or OMT + MT groups (Table I). At the end of the sub-chronic toxicity study, there were no histological changes observed in the control group (Fig. 2A), while mild centrilobular hypertrophy (areas circled with white dotted lines) in the liver was observed in the OMT (Fig. 2B) and MT (Fig. 2C) groups, and moderate centrilobular hypertrophy (area circled with a black dotted line) was observed in the OMT + MT group (Fig. 2D). These histopathological results are consistent with our previous study on radix S.tonkinensis-induced hepatotoxicity (5).

Cytotoxic effects of OMT, MT and OMT + MT on AML12 liver cells. To determine the cytotoxicity of treatment with OMT, MT and OMT + MT, a CCK-8 assay was used in AML12 cells treated with different concentrations of OMT $(10,20,30$ and $40 \mathrm{mM}), \operatorname{MT}(10,14,18,22,26$ and $30 \mathrm{mM})$ or OMT + MT $\left(10,14,18,22,26\right.$ and $30 \mathrm{mM}$ each) for $24 \mathrm{~h}$. A modified $\log _{10}$ [dose]-response curve was applied to fit the data and obtain the $\mathrm{IC}_{50}$ values. $\mathrm{IC}_{50}$ value is defined as the concentration of a molecule that inhibits $50 \%$ of the measured response (24). The data indicated that cell viability was not significantly altered by incubation with OMT for $24 \mathrm{~h}(10,20,30$ and $40 \mathrm{mM}$; $83.27 \pm 0.35,78.77 \pm 0.65,78.35 \pm 0.39$ and $77.24 \pm 0.46 \%$, respectively; expressed as the percentage of control cells; Fig. 3). Treatment with MT and OMT + MT induced cytotoxicity in a dose-dependent manner. At the end of the 24-h treatment period, incubation with 10, 14, 18, 22, 26 and $30 \mathrm{mM}$ of MT reduced cell viability (expressed as percentage of control cells) to $79.73 \pm 1.04,72.45 \pm 0.49,62.00 \pm 1.42,43.78 \pm 2.21,19.77 \pm 1.61$ and $10.02 \pm 0.44 \%$, respectively (Fig. 3). Under the same concentration conditions, cell viability of OMT + MT-treated cells decreased to $82.59 \pm 0.37,77.28 \pm 2.36,37.39 \pm 1.60$, $13.38 \pm 0.77,11.31 \pm 1.04$ and $8.84 \pm 0.09 \%$, respectively (Fig. 3). The $\mathrm{IC}_{50}$ values of MT and OMT + MT in this assay, calculated using the SigmaPlot 11.0 software, were 18.98 and $16.51 \mathrm{mM}$, respectively. However, the $\mathrm{IC}_{50}$ value for OMT could not be determined with the treatment concentrations used in the present study. These results suggest that OMT had no marked cytotoxic effect on AML12 liver cells compared with MT and OMT + MT groups. The left shift in the $\mathrm{IC}_{50}$ value for 

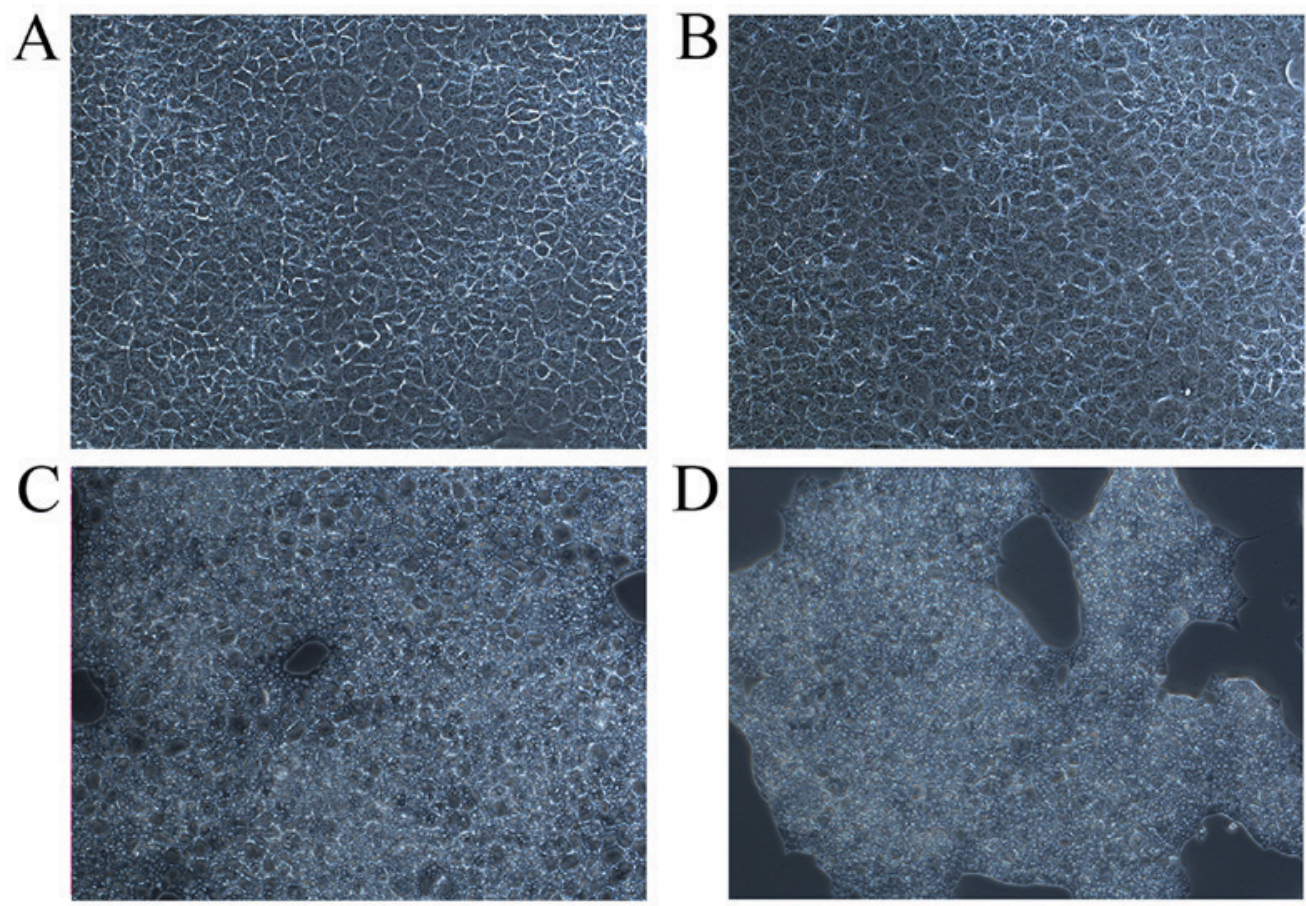

Figure 4. Comparison of cell morphology after $6 \mathrm{~h}$ treatment with OMT, MT or OMT + MT in AML12 liver cells (magnification, x200). (A) Control cells exhibited normal morphology and uniform distribution. (B) After treatment with $18 \mathrm{mM}$ OMT, the morphology and structure of the cells was generally intact. (C) After treatment with $18 \mathrm{mM} \mathrm{MT}$, the cell outline became less distinct, vacuolation occurred and the size of the cytoplasm decreased. (D) After treatment with $16 \mathrm{mM} \mathrm{OMT} \mathrm{+} \mathrm{MT,} \mathrm{some} \mathrm{of} \mathrm{the} \mathrm{cells} \mathrm{were} \mathrm{damaged,} \mathrm{suspended} \mathrm{or} \mathrm{missing.} \mathrm{OMT,} \mathrm{oxymatrine;} \mathrm{MT,} \mathrm{matrine.}$

treatment with OMT + MT implied a relatively high toxicity compared with the MT group, suggesting that OMT with MT may have a synergistic effect and enhance the hepatotoxicity in AML12 liver cells.

Effects of OMT, MT and OMT + MT on ALT, AST and $L D H$ leakage in the culture medium of AML12 liver cells. Light microscopy examination revealed different histological alterations in AML12 cells after $6 \mathrm{~h}$ of treatment with OMT, MT and OMT + MT. Cells exhibited intact morphology and structure in the control group (Fig. 4A) and following treatment with $18 \mathrm{mM}$ OMT (Fig. 4B). Certain pathological alterations, including shrinkage, unclear contour and vacuolar degeneration, were observed in the $18 \mathrm{mM} \mathrm{MT}$ group (Fig. 4C). In the group treated with $16 \mathrm{mM} \mathrm{OMT}+\mathrm{MT}$, the cell number was visibly reduced (Fig. 4D). These results suggest that MT alone or combined with OMT may increase cell injury and cause cell death.

Hepatotoxicity in vitro can be directly determined by measuring the levels of the aforementioned enzymes released into the culture medium (25). Cytotoxic results may provide important preliminary data for selecting a dosage for enzyme leakage tests in vitro (26). As indicated in Table II, treatment with 12 and $18 \mathrm{mM}$ MT significantly increased ALT, AST and $\mathrm{LDH}$ release $(\mathrm{P}<0.05$ or $\mathrm{P}<0.01)$ in a dose-dependent manner at 3,6, 12 and $24 \mathrm{~h}$, with the exception of ALT release following treatment with $12 \mathrm{mM} \mathrm{MT}$ at $24 \mathrm{~h}$. Furthermore, treatment with $4 \mathrm{mM} \mathrm{OMT}+\mathrm{MT}$ was observed to have no effect on ALT, AST and LDH release (Table III). In the cells treated with $16 \mathrm{mM} \mathrm{OMT}+\mathrm{MT}$, the levels of ALT, AST and LDH significantly increased $(\mathrm{P}<0.01)$ at $3 \mathrm{~h}$, peaked at $6 \mathrm{~h}$, and declined thereafter (Table III). However, in the
$10 \mathrm{mM}$ OMT + MT group, the levels of ALT, AST and LDH $(\mathrm{P}<0.05$ or $\mathrm{P}<0.01)$ peaked at $3 \mathrm{~h}$, and then decreased gradually over time (Table III). By contrast, when the cells were treated with OMT (18 mM) only, no significant increases in the three enzymes were observed over exposure periods of $3,6,12$ or $24 \mathrm{~h}(\mathrm{P}>0.05)$, with the exception of the level of AST, which significantly decreased compared with the control at $24 \mathrm{~h}(\mathrm{P}<0.01$; Table IV $)$. The above toxic effects of MT and OMT + MT may reflect cellular leakage and loss of functional integrity of liver cell membranes in a dose-dependent manner in AML12 liver cells subjected to $3,6,12$ and $24 \mathrm{~h}$ of incubation. Consistent with previous studies, the increased release of these intracellular enzymes indicate membrane damage and instability, owing to injury induced by xenobiotics $(25,27)$. The results of the current study indicate that MT and OMT + MT, but not OMT, may induce cell membrane damage.

\section{Discussion}

Several notable observations were made in the current study: i) Treatment with OMT, MT and OMT + MT in the equivalent amounts contained in radix $S$. tonkinensis induced hepatotoxicity; ii) the toxicity of OMT was weaker compared with MT in vitro; however, OMT-induced hepatotoxicity was consistent with that following treatment with MT in mice; and iii) OMT and MT in combination may serve a synergistic role in hepatotoxicity. These results support the hypothesis that MT and OMT are the toxic constituents responsible for the hepatotoxicity of radix S. tonkinensis, and the active metabolite MT transformed from OMT may be responsible for the toxic effect of OMT. 
Table II. Comparison of enzyme activities after 3, 6, 12 and 24 h treatment with MT in AML12 liver cells.

\begin{tabular}{|c|c|c|c|c|}
\hline Group & Time, $\mathrm{h}$ & ALT, IU/1 & AST, IU/l & LDH, IU/1 \\
\hline \multirow[t]{4}{*}{ Control $(n=6)$} & 3 & $0.00 \pm 0.00$ & $3.33 \pm 0.21$ & $15.83 \pm 0.70$ \\
\hline & 6 & $0.17 \pm 0.17$ & $3.33 \pm 0.21$ & $13.83 \pm 0.54$ \\
\hline & 12 & $0.17 \pm 0.17$ & $3.17 \pm 0.17$ & $13.33 \pm 0.42$ \\
\hline & 24 & $0.67 \pm 0.21$ & $2.83 \pm 0.17$ & $13.33 \pm 0.33$ \\
\hline \multirow[t]{4}{*}{ MT, 6 mM (n=4) } & 3 & $0.00 \pm 0.00$ & $2.75 \pm 0.63$ & $14.50 \pm 1.32$ \\
\hline & 6 & $0.00 \pm 0.00$ & $3.25 \pm 0.48$ & $15.25 \pm 0.85$ \\
\hline & 12 & $0.00 \pm 0.00$ & $3.00 \pm 0.41$ & $14.25 \pm 0.63$ \\
\hline & 24 & $0.00 \pm 0.00$ & $2.75 \pm 0.25$ & $12.25 \pm 0.25$ \\
\hline \multirow[t]{4}{*}{ MT, $12 \mathrm{mM}(\mathrm{n}=4)$} & 3 & $3.75 \pm 1.25^{\mathrm{b}}$ & $12.00 \pm 2.68^{b}$ & $75.75 \pm 17.88^{a}$ \\
\hline & 6 & $1.00 \pm 0.00^{\mathrm{a}}$ & $5.50 \pm 0.65^{\mathrm{a}}$ & $37.00 \pm 6.26^{\mathrm{a}}$ \\
\hline & 12 & $2.75 \pm 1.49^{\mathrm{a}}$ & $10.25 \pm 4.27^{b}$ & $76.75 \pm 36.44^{\mathrm{a}}$ \\
\hline & 24 & $1.25 \pm 0.25$ & $5.00 \pm 0.41^{\mathrm{a}}$ & $32.75 \pm 5.76^{\mathrm{b}}$ \\
\hline \multirow[t]{4}{*}{ MT, $18 \mathrm{mM}(\mathrm{n}=4)$} & 3 & $10.5 \pm 1.71^{b}$ & $25.50 \pm 3.01^{\mathrm{b}}$ & $188.00 \pm 23.28^{\mathrm{a}}$ \\
\hline & 6 & $10.00 \pm 0.91^{\mathrm{b}}$ & $22.50 \pm 1.19^{\mathrm{b}}$ & $147.50 \pm 10.97^{\mathrm{a}}$ \\
\hline & 12 & $14.5 \pm 1.49^{b}$ & $25.75 \pm 2.75^{b}$ & $151.00 \pm 32.45^{\mathrm{a}}$ \\
\hline & 24 & $17.75 \pm 2.95^{\mathrm{b}}$ & $26.75 \pm 1.55^{\mathrm{b}}$ & $176.50 \pm 20.39^{b}$ \\
\hline
\end{tabular}

${ }^{\mathrm{a}} \mathrm{P}<0.05$ and ${ }^{\mathrm{b}} \mathrm{P}<0.01$ vs. control group at a respective time point. MT, matrine; ALT, alanine aminotransferase; AST, aspartate aminotransferase; LDH, lactic dehydrogenase.

Table III. Comparison of enzyme activities after 3, 6, 12 and $24 \mathrm{~h}$ treatment with OMT + MT in AML12 liver cells.

\begin{tabular}{|c|c|c|c|c|}
\hline Group & Time, $\mathrm{h}$ & ALT, IU/1 & AST, IU/1 & LDH, IU/1 \\
\hline \multirow[t]{4}{*}{ Control $(n=6)$} & 3 & $0.00 \pm 0.00$ & $3.33 \pm 0.21$ & $15.83 \pm 0.70$ \\
\hline & 6 & $0.17 \pm 0.17$ & $3.33 \pm 0.21$ & $13.83 \pm 0.54$ \\
\hline & 12 & $0.17 \pm 0.17$ & $3.17 \pm 0.17$ & $13.33 \pm 0.42$ \\
\hline & 24 & $0.67 \pm 0.21$ & $2.83 \pm 0.17$ & $13.33 \pm 0.33$ \\
\hline \multirow[t]{4}{*}{$\mathrm{OMT}+\mathrm{MT}, 4 \mathrm{mM}(\mathrm{n}=4)$} & 3 & $0.00 \pm 0.00$ & $3.00 \pm 0.00$ & $15.50 \pm 0.65$ \\
\hline & 6 & $0.00 \pm 0.00$ & $3.25 \pm 0.25$ & $14.75 \pm 1.11$ \\
\hline & 12 & $0.00 \pm 0.00$ & $3.25 \pm 0.25$ & $15.25 \pm 0.95$ \\
\hline & 24 & $0.00 \pm 0.00$ & $3.00 \pm 0.00$ & $13.00 \pm 0.41$ \\
\hline \multirow[t]{4}{*}{$\mathrm{OMT}+\mathrm{MT}, 10 \mathrm{mM}(\mathrm{n}=4)$} & 3 & $4.75 \pm 1.55^{\mathrm{b}}$ & $13.75 \pm 3.71^{\mathrm{b}}$ & $98.75 \pm 26.73^{\mathrm{a}}$ \\
\hline & 6 & $2.00 \pm 0.41^{\mathrm{b}}$ & $6.75 \pm 0.48^{\mathrm{b}}$ & $40.25 \pm 2.25^{\mathrm{b}}$ \\
\hline & 12 & $1.25 \pm 0.25^{\mathrm{a}}$ & $6.25 \pm 0.48^{b}$ & $38.00 \pm 2.48^{\mathrm{a}}$ \\
\hline & 24 & $0.25 \pm 0.25$ & $3.25 \pm 0.25$ & $17.00 \pm 0.71^{\mathrm{a}}$ \\
\hline \multirow{4}{*}{$\mathrm{OMT}+\mathrm{MT}, 16 \mathrm{mM}(\mathrm{n}=4)$} & 3 & $14.00 \pm 0.91^{\mathrm{b}}$ & $33.50 \pm 1.19^{b}$ & $271.50 \pm 4.66^{\mathrm{b}}$ \\
\hline & 6 & $17.50 \pm 1.50^{\mathrm{b}}$ & $43.00 \pm 3.76^{\mathrm{b}}$ & $269.25 \pm 9.93^{\mathrm{b}}$ \\
\hline & 12 & $10.50 \pm 2.50^{\mathrm{b}}$ & $27.50 \pm 4.66^{\mathrm{b}}$ & $168.00 \pm 33.34^{\mathrm{b}}$ \\
\hline & 24 & $10.00 \pm 2.65^{\mathrm{b}}$ & $20.75 \pm 6.20^{\mathrm{b}}$ & $140.00 \pm 44.56^{\mathrm{b}}$ \\
\hline
\end{tabular}

${ }^{\mathrm{a}} \mathrm{P}<0.05$ and ${ }^{\mathrm{b}} \mathrm{P}<0.01 \mathrm{vs}$. control group at a respective time point. OMT, oxymatrine; MT, matrine; ALT, alanine aminotransferase; AST, aspartate aminotransferase; LDH, lactic dehydrogenase.

The increased release of liver enzymes, including ALT, AST and LDH, as well as TBiL, is recognized as an initial indicator of physiological dysfunction and liver toxicity $(22,28)$. However, hepatic histopathological evaluation is currently the standard method for determining the degree of liver injury during exposure to xenobiotics (29).
Levels of serum biochemical parameters may be used to predict the level of histological damage in the liver $(30,31)$. However, the alterations in the levels of these enzymes and TBil in the mice were not dose-dependent and were within the normal range for the species utilized in the present study (23). Therefore, pathological changes in the 
Table IV. Comparison of enzyme activities after 3, 6, 12 and $24 \mathrm{~h}$ treatment with OMT in AML12 liver cells.

\begin{tabular}{lcccc}
\hline Group & Time, $\mathrm{h}$ & ALT, IU/l & AST, IU/l & LDH, IU/l \\
\hline Control $(\mathrm{n}=4)$ & 3 & $2.50 \pm 0.50$ & $6.00 \pm 0.41$ & $32.25 \pm 1.44$ \\
& 6 & $2.25 \pm 0.25$ & $6.00 \pm 0.41$ & $43.50 \pm 4.33$ \\
& 12 & $2.50 \pm 0.29$ & $7.25 \pm 0.25$ & $61.50 \pm 15.20$ \\
OMT, $18 \mathrm{mM}(\mathrm{n}=4)$ & 24 & $1.25 \pm 0.25$ & $8.00 \pm 0.00$ & $24.25 \pm 0.25$ \\
& 3 & $2.50 \pm 0.29$ & $6.00 \pm 0.41$ & $36.00 \pm 3.39$ \\
& 6 & $2.50 \pm 0.29$ & $6.75 \pm 0.48$ & $59.50 \pm 5.36$ \\
& 12 & $2.75 \pm 0.25$ & $7.50 \pm 0.50$ & $68.75 \pm 5.62$ \\
& 24 & $1.00 \pm 0.00$ & $5.50 \pm 0.29^{\mathrm{a}}$ & $21.25 \pm 1.11$
\end{tabular}

${ }^{\mathrm{a}} \mathrm{P}<0.01$ vs. control group at a respective time point. OMT, oxymatrine; ALT, alanine aminotransferase; AST, aspartate aminotransferase; LDH, lactic dehydrogenase.

liver were also evaluated to verify this result. Centrilobular hypertrophy, characterized by the enlargement of both the cytoplasm and nucleus in the affected hepatocytes (32), was consistent with the histopathological results reported previously in radix $S$. tonkinensis-induced hepatotoxicity (5). This supported the hypothesis that OMT and MT are responsible for the hepatotoxicity of radix S. tonkinensis. It has also been reported previously that hepatocellular hypertrophy, in the absence of other histological findings, is not always associated with changes in serum ALT activity or other measured serum hepatic enzymes (33).

Centrilobular hepatocellular hypertrophy, the most common histological change associated with enzyme induction in animals, may be considered as an adaptive effect (33). However, this adaptive response may be overcome following exposure to intense or prolonged stimuli, leading to hepatocellular degeneration, necrosis or proliferation (34). The extent and degree of hepatotoxicity may depend on the duration of exposure (35). Indeed, the duration of exposure in the present study may have affected the results. Treatment with MT and OMT over 90 days may induce more severe liver injury compared with that of centrilobular hepatocellular hypertrophy presented in MT, OMT or MT + OMT treated groups in the current study. OMT and MT were identified in radix S. tonkinensis, Sophorae flavescentis and the above ground portion of Sophora alopecuroides, and these herbal remedies are also commonly prescribed for a number of illnesses $(36,37)$. Therefore, it is recommended that increased attention is paid to the hepatotoxicity of herbs containing MT and OMT when applying them for an extended period of time, as it is generally believed that herbal products are harmless and can be taken for a long period of time $(38,39)$.

Having identified that the hepatotoxic effect of radix S. tonkinensis is primarily caused by OMT or its metabolite MT, the effects on cell viability and the release of three enzymes in vitro were subsequently evaluated. The AML12 cell line was originally established from normal hepatocytes obtained from a CD1 male mouse strain, and the cells exhibit typical hepatocyte features, including peroxisomes and bile canalicular-like structures $(40,41)$. It was observed that MT and OMT + MT induced cell membrane damage and instability in vitro, while OMT had marked cytotoxic effect. It has been previously reported that following administration of OMT oral solution, the concentration of MT was significantly greater compared with OMT, indicating that only a small proportion of the oral solution is absorbed by the gastrointestinal tract, while most of the OMT is absorbed after it arrives in the intestines and is rapidly transformed into the metabolite MT $(16,42)$. By contrast, it was reported that only a small amount of OMT is transformed into metabolite MT following intravenous administration of OMT, as indicated by the area under the plasma concentration-time curve (17). These results indicate that the active metabolite MT, originating from OMT, may be the actual toxic substance in radix S. tonkinensis.

The combined toxicity of OMT and MT was also of interest in the current study. Previous evidence indicated that combined treatment with OMT and MT could increase the mortality rate in mice during a median lethal dose test, suggesting that combined treatment with OMT and MT exhibited a synergistic effect on toxicity (43). Therefore, it may be hypothesized that OMT combined with MT is more toxic for liver compared with OMT or MT alone.

The current study contributed to the better understanding the hepatotoxicity of radix S. tonkinensis and may have implications for its application in clinical settings. However, the present results are limited to the administration of MT and OMT for evaluating hepatotoxicity of radix S. tonkinensis. The effects of the non-alkaloid part of this herb on the liver require further investigation. It will also be important to evaluate long-term effects ( $>3$ months) of administration of MT and OMT on histological changes in the liver. Following prolonged exposure, the liver damage may be more severe compared with that observed in the current study. In addition, a number of studies reported that the increased centrilobular hepatocellular hypertrophy is likely due to the observed induction of hepatic cytochrome P450 (CYP450) enzymes, notably cytochrome P450 2B (CYP2B) (44-46). CYP450 participates in liver injury on various levels, including hepatocellular apoptosis, necrosis or aberrant proliferation $(47,48)$. Therefore, an evaluation of the change in CYP450 and CYP2B may be valuable to comprehensively understand the pathogenesis of exposure to MT and OMT in our future study. 
To the best of our knowledge, the current study demonstrated for the first time that administration of OMT and MT alone or simultaneously can induce hepatotoxicity at the dose equivalent to that contained in radix $S$.tonkinensis at a hepatotoxic dose, and MT and OMT are likely the hepatotoxic components of this herb. The results revealed that OMT induced hepatotoxicity in vivo, and this toxic effect may be primarily exerted by active metabolite MT. In addition, OMT in combination with MT was more toxic compared with MT or OMT alone. Since OMT may be transformed into the active metabolite MT by intestinal bacteria, the hepatotoxicity of OMT should be closely monitored when OMT is administered orally instead of intravenously. The current results improve the understanding of hepatotoxicity induced by radix $S$. tonkinensis, and provide insight into the actual hepatotoxic components among its main active ingredients.

\section{Acknowledgements}

Not applicable.

\section{Funding}

The present study was supported by funds from Shanghai University of Traditional Chinese Medicine (grant no. 2014YSN24), National Natural Science Foundation of China (grant nos. 81574078 and 81072646) and National Key Research and Development Program of China (grant no. 2017YFC1702000).

\section{Availability of data and materials}

All data generated or analyzed during the present study are included in this published article.

\section{Authors' contributions}

XT designed the experiments and wrote the manuscript. ZZ performed hepatic histopathological evaluation and wrote the histopathological result section of the manuscript. YG, JL, WS, RJ and TO performed the experiments and analyzed the data. All authors read and approved the final manuscript.

\section{Ethics approval and consent to participate}

The present study was approved by the Animal Ethics Committee of Shanghai University of Treditional Chinese Medicine (Shanghai China; certificate no. SZY201504021), and performed in accordance with the Guidelines for the Care and Use of Laboratory Animals (National Institutes of Health, Bethesda, MD, USA).

\section{Patient consent for publication}

Not applicable.

\section{Competing interests}

Toko Ohira is currently an employee of Shanghai Innostar Biotech Co., Ltd. (Shanghai, China), but had no competing interests. The remaining authors declare that they have no competing interests.

\section{References}

1. The State pharmacopoeia commission of P.R. China: Pharmacopoeia of the People's Republic of China. Chin Med Sci Press, Beijing, pp27, 2015 (In Chinese).

2. Tian XS: Research progress on toxicity of alkaloids in sophorae tonkinensis radix et rhizoma. Zhongguo Shi Yan Fang Ji Xue Za Zhie 22: 230-234, 2016 (In Chinese).

3. Wang XP and Yang RM: Movement disorders possibly induced by traditional Chinese herbs. Eur Neurol 50: 153-159, 2003.

4. Li X, Luan Y, Li X and Sun R: Study on anti-inflammatory efficacy accompanied by side effects of different components of Sophorae Tonkinensis Radix et Rhizoma. Zhongguo Zhong Yao Za Zhi 37: 2232-2237, 2012 (In Chinese).

5. Wang L, Lu J, Sun W, Gu Y, Zhang C, Jin R, Li L, Zhang Z and Tian X: Hepatotoxicity induced by radix Sophorae tonkinensis in mice and increased serum cholinesterase as a potential supplemental biomarker for liver injury. Exp Toxicol Pathol 69: 193-202, 2017.

6. Lee JW, Lee JH, Lee C, Jin Q, Lee D, Kim Y, Hong JT, Lee MK and Hwang BY: Inhibitory constituents of Sophora tonkinensis on nitric oxide production in RAW 264.7 macrophages. Bioorg Med Chem Lett 25: 960-962, 2015.

7. Lu ML, Xiang XH and Xia SH: Potential signaling pathways involved in the clinical application of oxymatrine. Phytother Res 30: 1104-1112, 2016.

8. Huang $\mathrm{J}$ and $\mathrm{Xu} \mathrm{H}$ : Matrine: Bioactivities and structural modifications. Curr Top Med Chem 16: 3365-3378, 2016.

9. Lu H, Zhang L, Gu LL, Hou BY and Du GH: Oxymatrine induces liver injury through JNK signalling pathway mediated by TNF- $\alpha$ in vivo. Basic Clin Pharmacol Toxicol 119: 405-411, 2016.

10. Gao ZW, Zhang RQ and Liao XH: Two cases of aggravating liver damage caused by oxymatrine injection in the patients with chronic hepatitis B. Yao Wu Bu Liang Fan Ying Za Zhi 2002: 120-121, 2002 (In Chinese).

11. Guo QP and Jin RM: Comparison of liver toxicity of matrine and oxymatrine in mice. Zhongguo Yao Li Yu Du Li Xue Za Zhi 30: 736-740, 2016 (In Chinese).

12. Chen Y, Zhang Q, Han SX, Han FM, Chen LM, Tong Y and You Y: Study on toxicity of different extractions of Sophorae tonkinensis. Zhongguo Yao Wu Jing Jie 14: 582-586, 2017 (In Chinese).

13. Miners JO, Knights KM, Houston JB and Mackenzie PI: In vitro-in vivo correlation for drugs and other compounds eliminated by glucuronidation in humans: Pitfalls and promises. Biochem Pharmacol 71: 1531-1539, 2006.

14. Chen P, Zhang X, Huang T, Yu Q and Cheng N: Metabolism of the hepatotoxic compound Sophoraflavanone $\mathrm{G}$ in rat liver microsomes. J Food Sci 79: T1462-T1468, 2014.

15. Xie MZ, Zhou WZ and Zhang YD: The metabolic fate of oxymatrine. Zhongguo Yao Li Xue Bao 16: 481-487, 1981 (In Chinese).

16. Wang ML, Zhou QL and Wang BX: Studies on metabolism of oxymatrine by human intestinal bacteria. Zhongguo Zhong Yao Za Zhi 26: 272-274, 2001 (In Chinese).

17. Wu XL, Hang TJ, Shen JP and Zhang YD: Determination and pharmacokinetic study of oxymatrine and its metabolite matrine in human plasma by liquid chromatography tandem mass spectrometry. J Pharm Biomed Anal 41: 918-924, 2006.

18. National Research Council (US) committee for the update of the guide for the care and use of laboratory animals: Guide for the care and use of laboratory animals. 8th edition. National Academies Press (US), Washington, DC, 2011.

19. Anon: The guidelines of test technology for long-term toxicity of chemical drugs. http://www.sfda.gov. cn/directory/web/WS01/images/u6Rp9Kpzu+zpMbatr7Q1MrU 0em8vMr11rilvNSt1PIucGRm.pdf (In Chinese).

20. Hou G, Xue L, Lu Z, Fan T, Tian F and Xue Y: An activated mTOR/p70S6K signaling pathway in esophageal squamous cell carcinoma cell lines and inhibition of the pathway by rapamycin and siRNA against mTOR. Cancer Lett 253: 236-248, 2007.

21. Amenya HZ, Gathumbi PK, Mbaria JM, Thaiyah AG and Thoithi GN: Sub-acute toxicity of the chloroformic extract of Rapanea melanophloeos (L.) Mez in rats. J Ethnopharmacol 154: 593-599, 2014. 
22. Akanda MR, Kim IS, Ahn D, Tae HJ, Tian W, Nam HH, Choo BK and Park BY: In vivo and in vitro hepatoprotective effects of Geranium koreanum methanolic extract via downregulation of MAPK/Caspase-3 pathway. Evid Based Complement Alternat Med 2017: 8137627, 2017

23. Serfilippi LM, Pallman DR and Russell B: Serum clinical chemistry and hematology reference values in outbred stocks of albino mice from three commonly used vendors and two inbred strains of albino mice. Contemp Top Lab Anim Sci 42: 46-52, 2003.

24. Tse DY, Chung I and Wu SM: Pharmacological inhibitions of glutamate transporters EAAT1 and EAAT2 compromise glutamate transport in photoreceptor to ON-bipolar cell synapses Vision Res 103: 49-62, 2014.

25. Shi C, Chen X, Liu Z, Meng R, Zhao X, Liu Z and Guo N: Oleuropein protects L-02 cells against $\mathrm{H}_{2} \mathrm{O}_{2}$-induced oxidative stress by increasing SOD1, GPx1 and CAT expression. Biomed Pharmacother 85: 740-748, 2017.

26. Sofi MS, Sateesh MK and Bashir M: Screening of the Ethnobotanicals against MDA-MB-231 and MCF-7 breast cancer cell lines. Int J of Phytopharm 4: 140-147, 2014.

27. Mani S, Mondal D, Sarma K and Singh K: Experimentally induced liver cirrhosis with ascites by carbon tetrachloride and phenobarbital sodium in wistar rats. Adv Anim Vet Sci 2 $159-163,2014$

28. Gowda S, Desai PB, Hull VV, Math AA, Vernekar SN and Kulkarni SS: A review on laboratory liver function tests. Pan Afr Med J 3: 17, 2009.

29. Acton QA: Drugs-advances in research and application: 2012 edition. Scholarly Editions, Atlanta, GA, pp645, 2012.

30. Kleiner DE, Chalasani NP, Lee WM, Fontana RJ, Bonkovsky HL, Watkins PB, Hayashi PH, Davern TJ, Navarro V, Reddy R, et al: Hepatic histological findings in suspected drug-induced liver injury: Systematic evaluation and clinical associations. Hepatology 59: 661-670, 2014.

31. Kirisci O, Paksoy T, Caliskan A, Analan A, Ozkaya E, Kirmaci B, Tumer S, Citil R, Cikim G, Agirbas S, et al: The relationship between serum DNA levels and serological markers, Alt and Ast with liver histology in chronic hepatitis B patients. Acta Medica Mediterr 32: 1805-1811, 2016.

32. Senoh H, Katagiri T, Arito $H$, Nishizawa $T$, Nagano $K$, Yamamoto S and Matsushima T: Toxicity due to 2- and 13-wk inhalation exposures of rats and mice to N,N-dimethylformamide. J Occup Health 45: 365-375, 2003.

33. Ennulat D, Walker D, Clemo F, Magid-Slav M, Ledieu D, Graham M, Botts S and Boone L: Effects of hepatic drug-metabolizing enzyme induction on clinical pathology parameters in animals and man. Toxicol Pathol 38: 810-828, 2010.

34. Williams GM and Iatropoulos MJ: Alteration of liver cell function and proliferation: Differentiation between adaptation and toxicity. Toxicol Pathol 30: 41-53, 2002.

35. Cataudella E, Malaguarnera G, Gagliano C,Condorelli G, Antic T, Rampello L, Erdogan O, Rampello L and Malaguarnera M: Pesticides exposure and the management of acute hepatic injury. Acta Medica Mediterr 28: 245-252, 2012.
36. He X, Fang J, Huang L, Wang J and Huang X: Sophora flavescens Ait: Traditional usage, phytochemistry and pharmacology of an important traditional Chinese medicine. J Ethnopharmacol 172: $10-29,2015$

37. Yang J, Zhang L, Zhu G and Li L: Separation and enrichment of major quinolizidine type alkaloids from Sophora alopecuroides using macroporous resins. J Chromatogr B 945-946: 17-22, 2014.

38. Firenzuoli $\mathrm{F}$ and Gori L: Herbal medicine today: Clinical and research issues. Evid Based Complement Alternat Med 4 (Suppl 1): S37-S40, 2007.

39. Welz AN, Emberger-Klein A and Menrad K: Why people use herbal medicine: Insights from a focus-group study in Germany. Bmc Complem Altern Med 18: 92, 2018.

40. Wu JC, Merlino G and Fausto N: Establishment and characterization of differentiated, nontransformed hepatocyte cell lines derived from mice transgenic for transforming growth factor alpha. Proc Natl Acad Sci USA 91: 674-678, 1994.

41. Hassoun E and Mettling C: Dichloroacetate and trichloroacetate toxicity in AML12 cells: Role of oxidative stress. J Biochem Mol Toxicol 29: 508-512, 2015.

42. Fan R, Liu R, Ma R, Bi K and Li Q: Determination of oxymatrine and its active metabolite matrine in human plasma after administration of oxymatrine oral solution by high-performance liquid chromatography coupled with mass spectrometry. Fitoterapia 89: 271-277, 2013.

43. Song B, Han CX and Zhang HL: Toxicity of three Sophora flavescens Ait alkaloids to mice. Xi Bei Zhi Wu Xue Bao 29: 818-823, 2009 (In Chinese).

44. Sakamoto Y, Yoshida M, Tamura K, Takahashi M, Kodama Y and Inoue K: Dose-dependent difference of nuclear receptors involved in murine liver hypertrophy by piperonyl butoxide. J Toxicol Sci 40: 787-796, 2015.

45. Deguchi Y,YamadaT,Hirose Y,Nagahori H,Kushida M, Sumida K, Sukata T, Tomigahara Y, Nishioka K, Uwagawa S, et al: Mode of action analysis for the synthetic pyrethroid metofluthrin-induced rat liver tumors: Evidence for hepatic CYP2B induction and hepatocyte proliferation. Toxicol Sci 108: 69-80, 2009.

46. van der Ven LT, van de Kuil T, Verhoef A, Leonards PE, Slob W, Cantón RF, Germer S, Hamers T, Visser TJ, Litens S, et al: A 28-day oral dose toxicity study enhanced to detect endocrine effects of a purified technical pentabromodiphenyl ether (pentaBDE) mixture in Wistar rats. Toxicology 245: 109-122, 2008.

47. Nebert DW and Dalton TP: The role of cytochrome P450 enzymes in endogenous signalling pathways and environmental carcinogenesis. Nat Rev Cancer 6: 947-960, 2006.

48. Zhang X, Zong C, Zhang L, Garner E, Sugie S, Huang C, $\mathrm{Wu}$ W, Chang J, Sakurai T, Kato M, et al: Exposure of mice to 1,2-dichloropropane induces CYP450-dependent proliferation and apoptosis of cholangiocytes. Toxicol Sci 162: 559-569, 2018.

(†) $\Theta$ This work is licensed under a Creative Commons Attribution-NonCommercial-NoDerivatives 4.0 International (CC BY-NC-ND 4.0) License. 